\title{
ANÁLISE DAS ATIVIDADES DE COMÉRCIO E SERVIÇOS NA REGIÃO METROPOLITANA DE NATAL
}

\author{
ANALYSIS OF TRADE AND SERVICES ACTIVITIES IN THE NATAL'S \\ METROPOLITAN REGION
}

\author{
Elaine Carvalho de Lima ${ }^{1}$ \\ Calisto Rocha de Oliveira Neto ${ }^{2}$ \\ Érica Priscilla Carvalho de Lima $^{3}$
}

RESUMO: O presente trabalho analisa a dinâmica do setor terciário, a partir dos subsetores do comércio e serviços, adotando como variável chave o comportamento do emprego formal na Região Metropolitana de Natal- RMN. Evidencia-se a problemática da ordenação espacial por meio de uma revisão das teorias da localização das atividades econômicas, buscando entender a distribuição espacial dos núcleos urbanos. Em termos metodológicos, foi realizada uma revisão da literatura sobre a temática, utilizou-se como metodologia o Quociente Locacional, que permite determinar a distribuição espacial da variável emprego e também verifica as especializações produtivas. Os resultados mostraram a centralidade da cidade de Natal no que tange ao leque de serviços e atividades de comércio. No entanto, esse setor tem vários desafios para serem superados, por exemplo, alguns municípios apesar de fazerem parte da RMN não possuem uma maior integração e dinamismo econômico. Com exceção dos municípios de Parnamirim, São Gonçalo e Macaíba, que ao longo das últimas décadas passou por um grande processo de urbanização e, portanto, um maior crescimento do leque de serviços oferecidos.

Palavras-Chave: Setor terciário; medidas de localização; Região Metropolitana de Natal

ABSTRACT: The present study analyzes the dynamics of the tertiary sector,
based on the subsectors of commerce and services, adopting as a key variable
the behavior of formal employment in the Metropolitan Region of Natal-RMN.
The problem of spatial ordering is evidenced by a review of theories of the
localization of economic activities, seeking to understand the spatial distribution
of urban centers. In methodological terms, a review of the literature on the
subject was carried out, using as a methodology the Locational Quotient, which
allows determining the spatial distribution of the variable employment and also
verifies the productive specializations. The results showed the centrality of the
city of Natal in the range of services and trade activities. However, this sector

${ }^{1}$ Doutoranda em Economia pela Universidade Federal de Uberlândia. Mestre e graduada em Economia pela Universidade Federal do Rio Grande do Norte. E-mail: elainecarvalhoonline@hotmail.com

${ }^{2}$ Mestre e graduado em Economia pela UFRN. Graduando em Ciências Contábeis pela UFRN. E-mail: calisto_neto@hotmail.com.

3 Docente da Universidade do Estado do Rio Grande do Norte (UERN). Mestre em Estudos Urbanos e Regionais e graduada em economia pela Universidade Federal do Rio Grande do Norte (UFRN). E-mail: ericapriscillaufrn@hotmail.com. 
has several challenges to overcome, for example, some municipalities, although part of NMR, do not have greater economic integration and dynamism. With the exception of the municipalities of Parnamirim, São Gonçalo and Macaíba, which over the last decades has undergone a great process of urbanization and, therefore, a greater growth of the range of services offered.

Key Words: Third sector; measures of location; Natal's Metropolitan Area

\section{INTRODUÇÃO}

O padrão de mão-de-obra predominante numa região permite 0 conhecimento das condições de ocupação de determinada população e o nível de desenvolvimento dos setores da economia. Várias são as causas que podem explicar a aglomeração ou esvaziamento de indivíduos em determinado espaço, um dos principais é o emprego.

A importância do setor terciário para a geração de emprego e renda e como propulsor de um efeito multiplicador para outros setores vem ganhando destaque nos últimos anos. De acordo com a definição utilizada pelo IBGE, o setor terciário é representado pelas atividades de comércio e serviços. O desenvolvimento também aumenta a demanda desse setor, como os serviços financeiros, marketing, comunicação, negociação de contratos, planejamento.

O setor terciário possui uma peculiaridade, pois tem uma elasticidaderenda da demanda maior que um, ou seja, aumentos no nível de renda provocam um aumento da demanda por serviços em uma proporção maior que a renda. Dessa forma, podem-se intensificar as disparidades regionais, uma vez que, as regiões que dispõem de um maior nível de renda per capita podem tender a ter um setor de serviços mais representativo em comparação aos demais setores da economia.

Além dos aspectos mencionados, nota-se que a persistência das desigualdades no Brasil é algo recorrente e crítico no debate do desenvolvimento regional. Apesar do país ter passado por várias mudanças na sua estrutura produtiva, as desigualdades espaciais são manifestadas sejam nos níveis regionais ou nas próprias unidades federativas.

Nesse sentido, a preeminência do setor terciário na participação da economia pode ser configurar como um fator desfavorável no cenário das disparidades existentes nas regiões do Brasil. A partir dos pontos enunciados, o presente estudo adota concomitantemente uma dimensão setorial e espacial, pretendendo-se analisar a distribuição do emprego nas atividades do setor terciário na Região Metropolitana de Natal, identificando a distribuição e participação desse setor e os resultados deste no crescimento do emprego da Região Metropolitana de Natal - RMN ao longo das últimas décadas. Nesse sentido, a pergunta norteadora dessa pesquisa é a seguinte: qual é a distribuição espacial do emprego formal do setor terciário da RMN?

Entre as justificativas para a escolha da variável emprego, temos que se trata de um importante indicador para mensurar o desenvolvimento social de uma região, pois se configura como incremento na renda do trabalhador e novas alternativas de atuação no mercado de trabalho. Além disso, o emprego 
formal pode mostrar o comportamento das atividades econômicas em uma determinada região.

O trabalho está estruturado em mais quatro seções, além dessa parte introdutória. Na primeira seção é apresentada uma breve revisão teórica das principais contribuições sobre a temática das teorias de localização das atividades econômicas. A segunda seção apresenta a fundamentação sobre a importância do setor terciário, especialmente, o subsetor de serviços para o desenvolvimento econômico. Na terceira seção apresentam-se a metodologia do trabalho, bem como os principais resultados. Por fim, na última seção são apresentadas as conclusões do trabalho.

\section{A ESTRUTURA DO ESPAÇO URBANO: A CONTRIBUIÇÃO DAS TEORIAS LOCACIONAIS}

A discussão sobre a localização das atividades no espaço não é algo contemporâneo. Desde Marshall (1982), a relevância e a geração de vantagens competitivas a partir das aglomerações produtivas e das economias externas, estas constituídas por fatores que impactam a produtividade onde há a concentração geográfica dos produtores, vem sendo ressaltada. Nesse sentido, para o autor o crescimento econômico de uma região é atribuído, entre outros fatores, a formação de clusters.

Von Thunen (1873-1850) foi um dos pioneiros no estudo das teorias de localização das atividades econômicas. Thunen formula um modelo de localização agrícola e desenvolve sua análise através de círculos concêntricos, onde a localização das unidades produtivas em determinados pontos desses círculos está em função de dois elementos básicos: o custo de transporte e a renda da terra. Esses fatores se comportam de forma contrária, a renda da terra tem um papel de dispersão das atividades, no sentido em que é menor quanto maior for a distância do centro da cidade. Já o custo de transporte "empurra" no sentido de aglomeração, desempenhando a função de concentrador das atividades em um determinado espaço. Assim, nesse modelo, a localização das atividades se daria em um ponto de equilíbrio entre a renda da terra e o custo de transporte.

Com o processo de urbanização, as cidades ganham uma maior importância no ordenamento espacial. Um dos estudiosos que trouxe grandes contribuições em suas formulações teóricas foi o Walter Christaller, sua teoria teve um caráter inovador por analisar o crescimento de uma cidade individual e, principalmente, o seu entorno. Em sua obra, "Lugares Centrais no Sul da Alemanha" de 1933, o autor estuda a organização das atividades econômicas no espaço, em que o crescimento da cidade está condicionado pela especialização dos serviços centrais, assim, a demanda por tais serviços determinará o crescimento dessa cidade.

Desse modo, as áreas de aglomeração produtiva se constituem como o Lugar Central, devido a importância de suas mercadorias e o alcance das zonas de comercialização, pois:

Alguns bens e serviços são encontrados virtualmente em qualquer lugar. Por menor que seja o lugar, alguns bens e serviços estão sempre disponíveis. Esse é o caso, por exemplo, do pequeno comércio de alimentos. Entretanto, no outro extremo, alguns bens e serviços são encontrados apenas nos grandes centros, tais como

Revista de Estudos Sociais | Ano 2017, N. 39, V. 20, Pag. 113 
serviços profissionais especializados ou shoppings. (CLEMENTE, 1994, p. 82).

Christaller também enfatiza a noção de hierarquia que revela a existência de lugares centrais de ordem superior e lugares centrais de ordem inferior. A centralidade da cidade está intrinsecamente relacionada com a função da cidade de se constituir no núcleo de uma região, bem como na oferta de bens e serviços que necessitam está localizados centralmente, como o comércio, universidades, administração pública, serviços bancários, entre outros. Conhecida como "região complementar", a área do entorno da localidade central, é caracterizada por ser uma área agrícola, portanto, depende da cidade para a obtenção de bens e serviços necessários, e por outro lado, oferece para as cidades os principais alimentos.

Alfred Weber desenvolveu seu estudo a partir de um modelo de localização industrial, três fatores essenciais são levados em consideração na decisão locacional, tais fatores podem ser subdivididos em gerais que são os custos de transporte e mão-de-obra e fator local que são as forças de aglomeração e desaglomeração. Ou seja, concentrar ou desconcentrar as indústrias em um ponto geográfico, a partir das vantagens existentes em determinada região.

Para Azzoni (1986), as economias de aglomeração se classificam em: economias de escala (redução dos custos unitários de uma firma, devido a expansão da escala de produção); economias de localização (a proximidade com outras firmas possibilitam redução dos custos unitários); e economia de urbanização (decorre do aumento do nível econômico onde há a localização da empresa). De modo geral, "o fator locacional constitui um ganho, uma redução de custos, que uma atividade econômica obtém, quando se localiza em um dado ponto. Certamente, seus custos totais seriam mais altos em outros locais" (HADDAD, 1989, pag. 78).

Outra contribuição importante é o modelo de August Losch, que tem sua análise do problema da localização a partir da visão do produtor e do consumidor. O modo de organização de seu modelo usa fatores comerciais e de transporte que se traduz em uma competição entre as cidades por uma maior área de mercado. Losch utiliza formas matemáticas para descrever sua análise, onde cada área de mercado possui a forma hexagonal, permitindo maior demanda e satisfazendo as necessidades dos consumidores locais. Assim, a localização ótima nesse modelo está relacionada as diferenças espaciais entre a oferta e a demanda, em que o consumidor possa adquirir produtos a preços mais baixos e o produtor tenha o maior lucro possível. Desse modo, haveria uma rede de áreas de mercado, por exemplo, conectados por uma rede de transportes. Isso levaria à aglomeração de atividades em um determinado lugar, e outras agindo no sentido de dispersão.

Para Santos (2003), na análise do desenvolvimento deve-se considerar o elemento tempo e o processo histórico da região, que poderá alterar o modo de organização das atividades no espaço geográfico. Esse modo de organização está relacionado com os hábitos, instituições, costumes, participação política, métodos empresariais e tomada de decisões. Tal análise corrobora com a apreciação de Corragio (1980) ao apresentar o processo de regionalização como resultado da divisão territorial do trabalho em uma sociedade através de sua realidade histórica. Desse modo, a região resulta da 
regionalização em âmbito social e deve ser estudada a partir da reprodução social. Ou seja, em uma sociedade capitalista, o elemento cerne é a reprodução do capital social.

Lipietz (1988) traz uma contribuição significativa para o estudo da região, em sua formulação teórica a região surge como produto das relações entre regiões, através da articulação do modo de produção dominante que distribui a divisão do trabalho entre as variadas regiões. Assim, as diferenças regionais não ocorrem de um "acaso histórico", mas sim devido as articulações das estruturas sociais e dos espaços que irão se influenciar. Desse modo, as diferentes interações entre empresas e consumidores nos mais variados espaços irão possibilitar a escolha de determinados lugares em detrimento dos demais.

Nas últimas décadas o estudo da distribuição das atividades econômicas no espaço geográfico ganhou um maior espaço para a investigação econômica. Nota-se que uma preocupação que permeia tais estudos está relacionada à existência de desigualdades regionais, em que a região passa a ser vista como um problema, desse modo a ciência regional (economia espacial) surge para atender aos problemas da região, buscando minimizar as consequências que as disparidades podem provocar nas regiões (BENKO, 1999).

Nesse contexto, o problema regional inicialmente tem relação com as desigualdades econômicas entre as regiões de um mesmo espaço e, posteriormente essa discussão se expande a nível mundial, evidenciando a dualidade entre os países desenvolvidos e subdesenvolvidos.

Alguns autores afirmam que o dualismo regional ameaça a estrutura da organização socioeconômica de uma nação. Para Myrdal (1968), em sua "Teoria da Causação Cumulativa", há um "hiato" crescente entre os diferentes espaços, pois o crescimento de uma região irá ocasionar efeitos regressivos em outras, isso é causado pelos movimentos de capital, mão-de-obra e de bens e serviços o que leva ao agravamento das disparidades regionais, de modo que o processo cumulativo pode se desenvolver para cima (efeitos propulsores) nas regiões mais desenvolvidas, ou para baixo (efeitos regressivos) nas regiões menos desenvolvidas.

Kon (2004) elucida que o desenvolvimento das atividades no espaço adquire um papel essencial na determinação das situações de sucesso ou atraso da região, permitindo que um determinado espaço possa apresentar condições que o qualifiquem, por exemplo, como um pólo industrial. Assim, nas atividades econômicas, a escolha da localização ótima é algo fundamental e aborda questões sobre a proximidade das matérias-primas, redução dos custos de produção, custo com transportes, aumento dos lucros, entre outros fatores. Para a autora, a dinâmica do desenvolvimento está alicerçada no processo de acumulação, concentração e centralização do capital, ocasionando alterações na estrutura produtiva da economia.

As economias regionais possuem particularidades que não podem ser consideradas como versões simplificadas das economias nacionais. Hirschman (1958) defende a importância de teorias próprias que abordem o processo de desenvolvimento regional, o autor enfatiza que os efeitos de transbordamento e polarização do crescimento ocorrem de modo mais intenso nas relações econômicas entre regiões nacionais do que relações internacionais, isso pode ser justificado pela interação mais forte existente entre as regiões

Revista de Estudos Sociais | Ano 2017, N. 39, V. 20, Pag. 115 
subnacionais. A próxima seção apresenta uma fundamentação teórica sobre a importância do setor terciário, especialmente, 0 de serviços para 0 desenvolvimento regional.

\section{A importância do setor de serviços para o desenvolvimento econômico}

Para a análise do desenvolvimento econômico da sociedade se faz necessário conhecer o comportamento dos setores econômicos, principalmente, para compreender a dinâmica das transformações em sua estrutura produtiva e a importância das transformações em tal processo de desenvolvimento

Historicamente, no papel do setor de serviços sobre o desenvolvimento econômico, verifica-se a forte relação da urbanização com o aumento das atividades desse setor, impulsionando um maior fluxo de pessoas, aumento da população e atividades nos centros urbanos.

O setor de serviços tem uma grande importância na economia mundial. A partir de meados dos anos 1980 esse setor passa a ganhar destaque em escala global, tornando-se a principal fonte de geração de empregos no pós crise do petróleo de 1973. Desse modo, a expansão do setor passa a ser vista como um meio das nações se ajustarem aos períodos de crise econômica KON (2004).

Importante destacar que o setor se identifica por distintos níveis de produtividade, incluindo desde subsetores do comércio até segmentos de elevado desempenho tecnológico, como é o caso das tecnologias de informação e comunicação (TICs), robótica e microeletrônica. Isto posto, observa-se que o setor pode ser propulsor para o desenvolvimento econômico, uma vez que, além de gerar emprego e renda, também viabiliza outros setores, em razão do aumento da produtividade e da propagação de inovações tecnológicas e organizacionais.

Ao longo das últimas décadas, ocorreram várias mudanças nas economias mundiais entre elas, a internacionalização das atividades econômicas, os avanços tecnológicos da informática, robótica, telecomunicações, mudanças no papel de intervenção do governo nos países, entre outros. Tais mudanças alteraram o setor de serviços, produzindo novas formas de relacionamento entre os produtores e consumidores.

Nesse sentido, o trabalho alcançou uma configuração hegemônica caracterizada pela mundialização do capital, projeto político fundamentado no neoliberalismo e pela reestruturação do trabalho. A nova fase que caracteriza o capitalismo contemporâneo é conhecida como acumulação flexível. De modo que, o capitalismo do século XIX não é o mesmo do século $X X$ e difere do século XXI (ALVES, 2007).

Um ponto importante a destacar é que a propagação de novos modelos produtivos ocorreu de forma lenta e desigual, envolvendo os diferentes países e regiões, setores e empresas. Em síntese, é possível verificar o despontar de uma divisão, que muitas vezes é desigual, bem como excludente, pois nem todas as regiões se tornam atrativas para essas atividades (DRUCK, 2011).

O desenvolvimento do setor terciário possui relevância na geração de emprego, contudo, o processo de desenvolvimento do setor levou a uma 
alteração do perfil do mercado de trabalho, a medida que passa-se a exigir maiores qualificações dos trabalhadores.

Diante disso, a natureza do setor terciário pode originar mecanismos de desenvolvimento e entrave entre as diversas localidades. Isso ocorre do aumento da complexidade dos segmentos que, em última instância, afeta o perfil da mão de obra necessária. Assim, as regiões que possuem maiores vantagens, seja em infraestrutura ou qualificação profissional, ocasiona uma segregação das regiões que não possuem tais vantagens.

As transformações que ocorreram em fins dos anos $1980 \mathrm{com}$ a reestruturação produtiva no país são marcadas por grandes discussões. Por um lado, alguns estudos defendem que o processo atrelado a abertura econômica impactou de modo positivo a produtividade, uma vez que possibilitou a redução de custos e incentivo a concorrência entre produtores nacionais e internacionais. Por outro lado, a abertura econômica acarretou na reestruturação industrial e, numa redução do tamanho médio das plantas e realocação das indústrias do país. Por conseguinte, o padrão industrial nacional passou a ter seu desempenho subordinado ao novo ambiente político econômico.

Nesse contexto, o setor de serviços assume um grau de importância como possível compensador da mão de obra que não fora absorvida nos demais setores. Isso pode ser justificado, entre outros motivos, pela incapacidade do setor primário em absorver um maior contingente populacional, bem como pela baixa absorção de trabalhadores na indústria devido as mudanças de automação do setor.

Para Kon (2004), existem algumas explicações para a análise do crescimento das atividades de serviços. Em primeiro lugar, teríamos as mudanças ocupacionais dos indivíduos, em que o processo de terceirização conduziria para uma sociedade de serviços. A segunda forma de análise afirma que a terceirização é uma consequência do declínio relativo e absoluto do emprego no setor secundário, que devido as inovações tecnológicas houve uma diminuição dos empregos, assim, o setor terciário iria absorver a mão-deobra dispensada. Por último, a redução do emprego no setor secundário, justifica-se pelo crescimento do emprego no setor público.

Ademais, o padrão de localização das atividades econômicas no Brasil é marcado por grandes heterogeneidades regionais. Tais características possibilitam diferenciar áreas mais dinâmicas e aquelas que não apresentam vantagens locacionais para atividades com um maior grau de competitividade.

Guimarães Neto (1997) chama atenção para o fato de que diante das diferenças entre as sub-regiões do Brasil, é fundamental a existência de políticas de desenvolvimento se adequem a realidade de cada sub-região, ou seja:

(...) ora enfatizando a maior disponibilidade de infraestrutura, ora a inovação tecnológica e a sua difusão em segmentos específicos, ora a formação, capacitação e treinamento da força de trabalho, ora a reestruturação produtiva de sub-regiões críticas. O que se propõe é o tratamento por meio de uma espécie de 'sintonia fina' que considere, simultaneamente com a 'mobilização local', as formas de interferência do poder público que possam consolidar ou despertar as potencialidades de cada sub-região. GUIMARÃES NETO (1997, p, 84).

Revista de Estudos Sociais | Ano 2017, N. 39, V. 20, Pag. 117 
O gráfico 1 ilustra a representatividade do setor terciário na economia brasileira, observa-se que em 2010, mais de $65 \%$ do PIB se encontrava nesse setor. Ao analisar o período de 2000 a 2010, o setor representou aproximadamente $60 \%$ do PIB do Brasil. Deste modo, a dinâmica de crescimento econômico do Brasil está atrelada ao comportamento do setor e sua distribuição espacial configura num importante elemento para a dinâmica regional.

Gráfico 1 - Participação do setor terciário no PIB (\%)

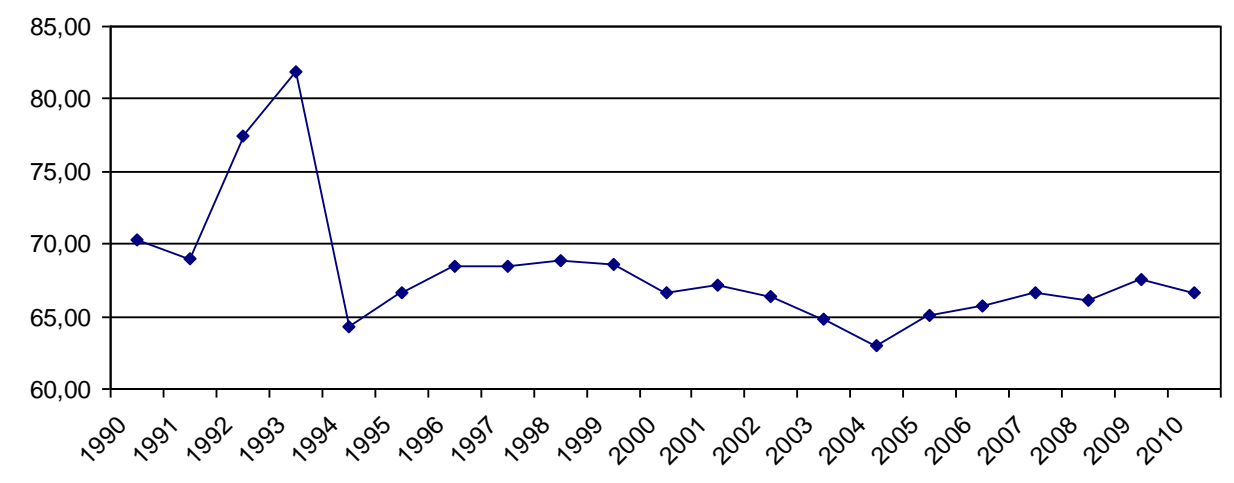

Fonte: IPEADATA (2016)

Além disso, o aumento da urbanização no país acarreta numa crescente oferta de serviços e comércio, o que evidencia a importância dessas atividades para o dinamismo econômico. Destacam-se o crescimento das atividades bancárias e financeiras, serviços de hospedagem e alimentação, entre outros.

A partir dos anos 1990, o setor de comércio passou por grandes mudanças no que se referem a uma maior concentração do setor, resultado de um maior peso dos grandes grupos que adquiriram as pequenas e médias redes comerciais, uma crescente concorrência e a entrada maciça de grupos internacionais.

\section{Região metropolitana de natal: um diagnóstico do setor de serviços}

No Brasil, a urbanização começou a se expandir a partir de meados dos anos 1950, ocorrendo uma mudança do padrão demográfico nas cidades, em que houve um inchaço populacional nos centros urbanos. O processo de metropolização brasileira se expandiu com o processo de urbanização do país, principalmente nas capitais dos estados, que expandiram o seu território em direção as áreas vizinhas.

A Região Metropolitana de Natal (RMN) possui dez municípios: CearáMirim, Extremoz, Macaíba, Monte Alegre, Natal, Nísia Floresta, Parnamirim, São Gonçalo do Amarante, São José do Mipibu e Vera Cruz. A RMN se destaca nas atividades do setor terciário, ou seja, comércio e serviços. Algumas atividades econômicas presentes nos municípios conferem a RMN um caráter heterogêneo do ponto de vista produtivo. Ainda há municípios com 
maiores concentrações populacionais na área rural, caracterizando-os economicamente pela produção agrícola.

O processo de metropolização da RMN teve início nos anos 1970, alguns fatores marcaram a atual organização espacial da região: instalações do Instituto Nacional de Pesquisas Espaciais (INPE); a construção do campus universitário- UFRN; chegada do Centro de lançamentos de foguetes de Barreira do Inferno, entre outros fatores. Em meados dos anos 1980, o turismo colaborou para a expansão do setor de serviços. Nesse mesmo período aparecem as redes nacionais de supermercados e a implementação do Projeto Via Costeira.

A partir dos anos 1990, houve um processo de reorganização espacial relacionada a atividade do turismo, bem como a dinâmica do setor terciário que teve impulso pela construção da BR 101, interligando o acesso às praias litorâneas. No período mais recente, o setor da construção civil tem dinamizado a economia da RMN, que contribuiu para a expansão da capital do estado do $\mathrm{RN}$. Tal dinâmica fez com que alguns municípios passassem por um processo de conurbação, como por exemplo, os municípios de Natal e Parnamirim.

Segundo dados do CENSO 2010, a RMN concentra cerca de aproximadamente $43 \%$ da população residente no Rio Grande do Norte. Natal, que é a capital do Rio Grande do Norte, concentra a maior parte da população e das atividades econômicas da RMN. Devido à densa ocupação dessa cidade que já atinge seus limites geográficos, o crescimento demográfico (expansão da ocupação) se dá de modo inferior aos demais municípios.

O setor terciário redefiniu a ordenação do espaço para garantir as atividades de serviços e comércio. De modo que houve uma reorganização da malha viária, fazendo com que o comércio se desenvolvesse em várias áreas da cidade de Natal, para além dos bairros tradicionais, como Alecrim e Cidade Alta.

Como visto na Teoria dos Lugares Centrais, a centralidade de uma cidade está relacionada com sua capacidade de oferecer bens e serviços para outras áreas, criando assim, uma área de influência. Nesse sentido, Natal se configura como núcleo central da RMN devido à importância econômica da cidade, além de concentrar a estrutura administrativa das esferas governamentais.

\section{METODOLOGIA}

Em termos metodológicos, além da revisão da literatura sobre a temática de estudo, foi utilizada as medidas de localização que "são medidas de natureza setorial e se preocupam com a localização das atividades entre as regiões" (HADDAD, 1989, p. 231).

O intuito é selecionar padrões de concentração ou dispersão espacial da variável-base selecionado, ou seja, emprego no setor de serviços. Para isso foram selecionados os anos de 1990, 2000 e 2010 na Região Metropolitana de Natal (RMN). A escolha por tal variável se justifica pela disponibilidade de dados desagregados setorialmente. Os dados foram obtidos junto a Relação Anual de Informações Sociais (RAIS) do Ministério do Trabalho e do Emprego (MTE). Com a finalidade de analisar o perfil urbano e a distribuição do emprego 
na RMN nos diversos setores, os indicadores possibilitam verificar as possíveis modificações locacionais ao longo do período escolhido para análise.

\section{A matriz de informações}

Para a organização das informações foi elaborada uma matriz, em que cada linha ilustra a distribuição total do emprego de um dado setor econômico entre os diferentes municípios da RMN, e cada coluna mostra como o emprego total dos municípios se distribuem entre os seus diferentes setores econômicos.

Na elaboração da matriz são definidos:

$E_{i j}=$ emprego no setor $i$ da região $j$;

$E_{. j}=\sum_{i} E_{i j}=$ emprego em todos os setores da região $j$;

$E_{i .}=\sum_{j} E_{i j}=$ emprego no setor $i$ de todas as regiões;

$E . .=\sum_{i} \sum_{j} E_{i j}=$ emprego em todos os setores de todas as regiões.

Figura 1- Matriz de Informações

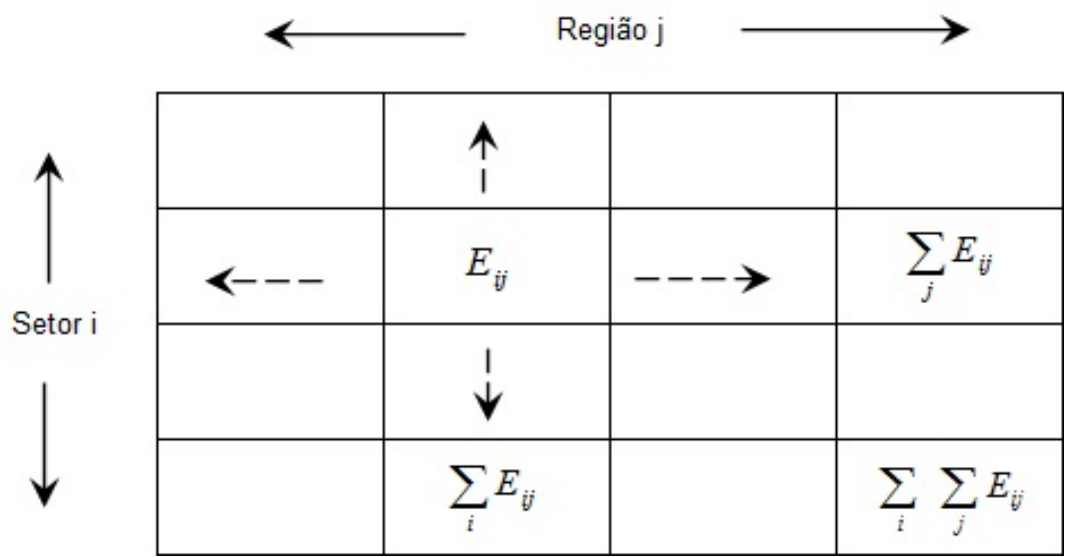

Fonte: Adaptado pela autora com base em Haddad (1989).

Desta matriz são derivadas outras duas que mostram, em percentual, a distribuição do emprego na RMN por setor produtivo e a distribuição do emprego de cada setor entre as regiões. Através da matriz pode-se calcular diferentes tipos de medidas que permitem descrever o comportamento dos setores econômicos no espaço:

$$
i^{e} j=\frac{E_{i j}}{\sum_{i} E i j}
$$


$j^{e} i=\frac{E_{i j}}{\sum_{j} E_{i j}}$

sendo: $\sum_{i} i^{e} j=1,00 ; \sum_{j} j^{e} i=1,00 ; i^{e} .=\sum_{j} i^{e} j ;$ e $j^{e} .=\sum_{i} j^{e} i$

\section{Medidas de localização}

Como mencionado, a utilização das medidas de localização permitem constatar a localização dos setores econômicos entre as regiões num dado período. Para o presente trabalho foi selecionado o Quociente Locacional.

\section{Quociente locacional}

O quociente locacional do setor $i$ na região $j$ é definido como:

$$
Q L_{i j}=\frac{E_{i j} / E_{i .}}{E_{. j} / E_{. .}}
$$

O quociente locacional (QL) compara a participação percentual de uma região, em um dos setores, com a participação percentual da mesma região, no total do emprego. Se o valor do quociente for maior do que 1, isto significa que a região é, relativamente, mais importante no contexto nacional, em termos do setor, do que em termos gerais de todos os setores.

\section{RESULTADOS E DISCUSSÃO}

\section{Mudanças estruturais na Região Metropolitana de Natal}

Ao longo das últimas décadas, houve significativos avanços nos estudos sobre a existência dos fenômenos espaciais. Como já enfatizado, Kon (2004) salienta que as mudanças ocupacionais nas últimas décadas resultaram num aumento das atividades de serviço, que entre outros fatores, está relacionado às mudanças tecnológicas.

A importância econômica da cidade de Natal em relação a RMN concede-lhe a condição de núcleo dessa região. Ao longo do período, a atividade turística com suas políticas de fomento teve grande contribuição para a economia dessa capital. Além disso, a concentrada estrutura administrativa estadual e federal. Portanto, verifica-se a existência de uma aglomeração urbana metropolizada, em um polo fortemente concentrador- Natal, com seu entorno dos 9 municípios vinculados a esse centro urbano. Na figura 2, pode ser visualizado a RMN:

Figura 2- Região Metropolitana de Natal 


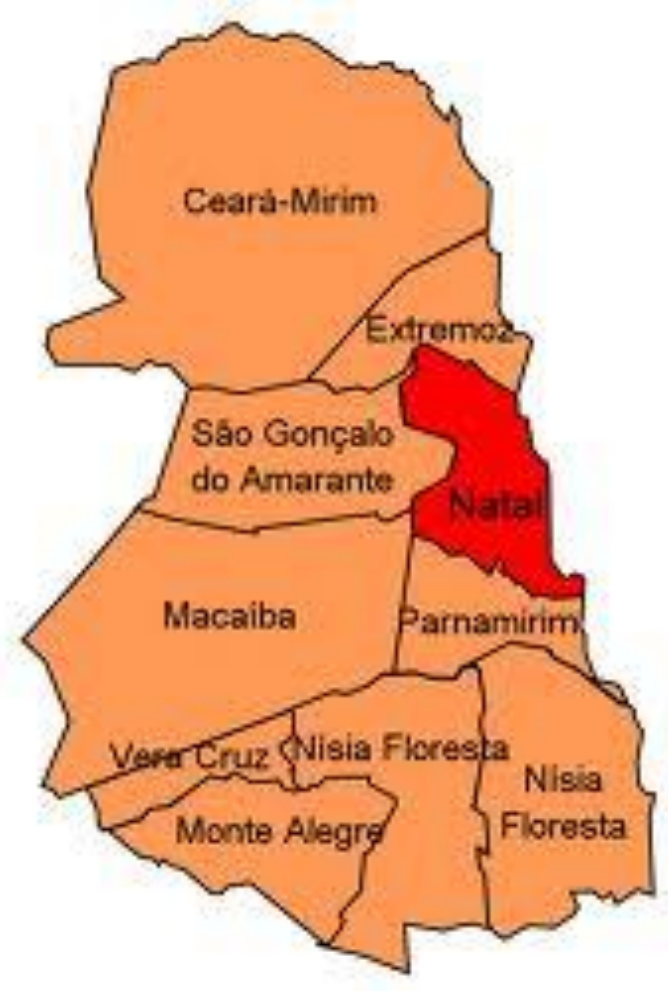

Fonte: Mapa base do IBGE

Quantos aos resultados, a cidade de Natal (figura 3) demonstrou um maior potencial para as atividades de serviços e comércio, de modo que ao longo dos anos vem tendo uma tendência de crescimento. O QL mostra essa especialização, com QL> 1,0 em todos os períodos. Os demais setores tiveram uma baixa concentração. Tal resultado corrobora com o que já se esperava na literatura, por ser a capital do estado do Rio Grande do Norte, a cidade de Natal possui um leque de serviços e comércio que garantem o atendimento das regiões vizinhas.

Figura 3 - Quociente Locacional dos setores econômicos para o município de Natal em 1990, 2000 e 2010

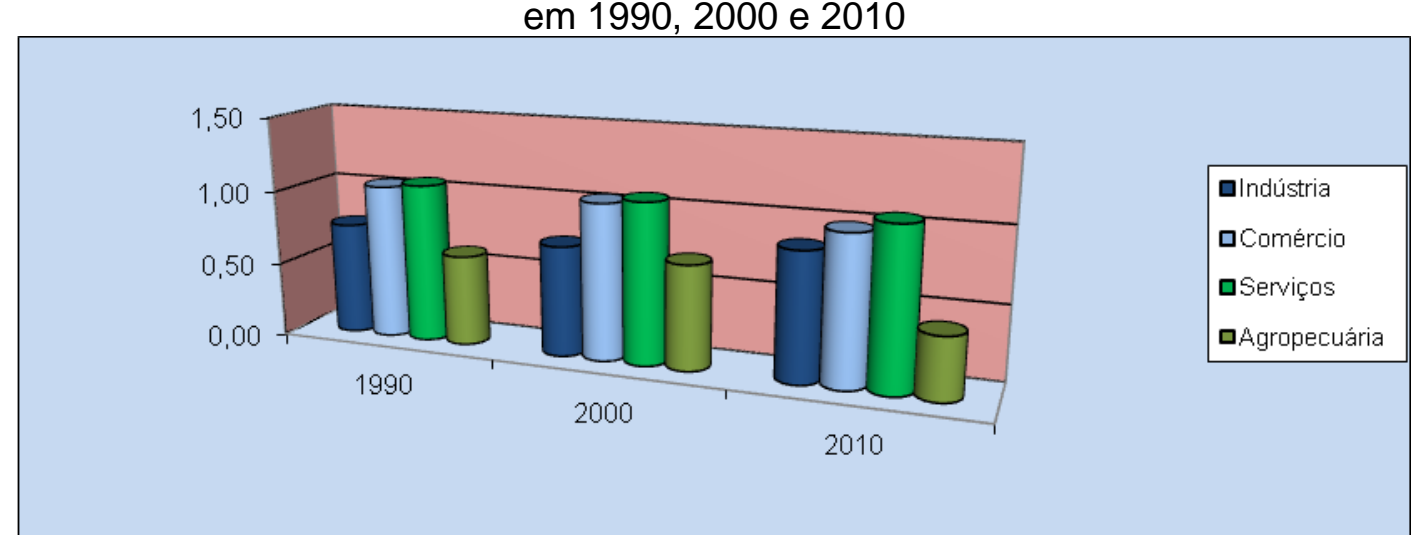

Fonte: Resultado da Pesquisa.

Quanto ao município de Parnamirim (figura 4), observou-se uma alta integração com a cidade de Natal, tal município demonstrou uma maior potencialidade para as atividades do setor agrícola em 1990, no entanto Revista de Estudos Sociais | Ano 2017, N. 39, V. 20, Pag. 122 
reduziu significativamente sua participação ao longo das últimas décadas. Tal fato pode ser justificado pelo crescimento urbano, o que aumenta a demanda pelo setor de serviços. Apesar de ter reduzido a participação no setor industrial no período analisado, em 2010 o QL desse setor era maior que 1. Assim, como o setor de Serviços, o setor de Comércio apresentou uma pequena elevação ao longo dos três períodos analisados, mantendo o $\mathrm{QL}>1,00$, empregando 23.491 trabalhados nesse setor no ano de 2010. Como ilustrado na tabela abaixo.

Figura 4 - Quociente Locacional dos setores econômicos para o município de Parnamirim em, 1990, 2000 e 2010

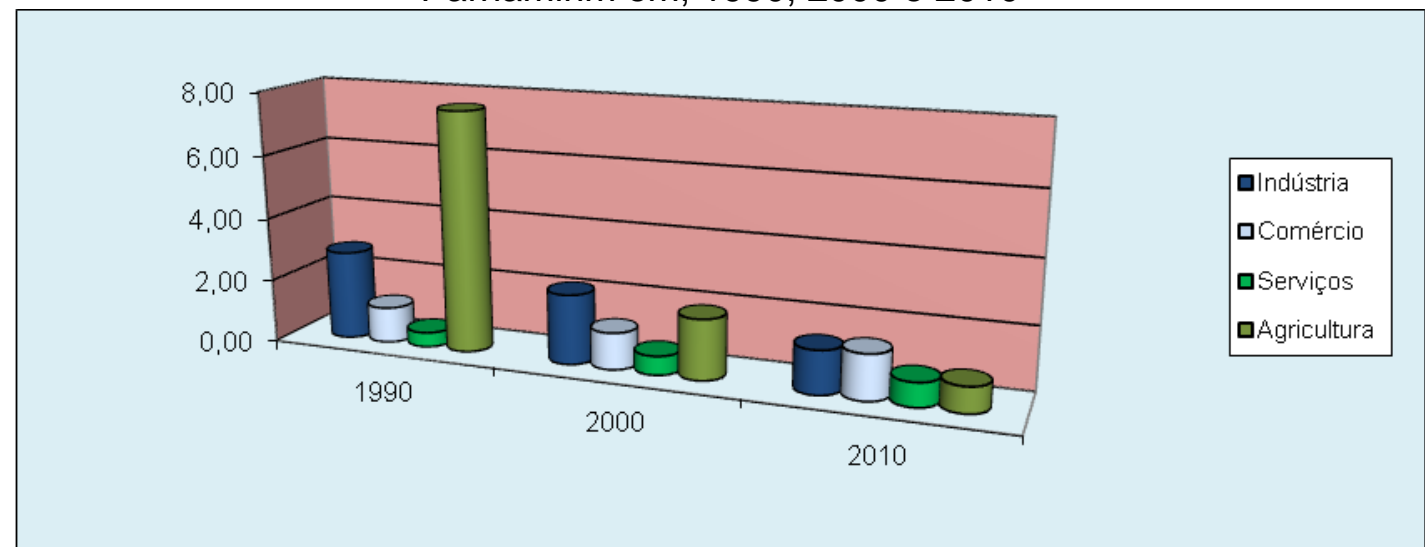

Fonte: Resultado da Pesquisa.

Assim como Parnamirim, o município de São Gonçalo do Amarante (figura 5) possui uma alta integração nas RMN. O setor de serviços teve uma elevação ao longo dos anos analisados, no entanto, o QL é pouco concentrado com QL igual a 0,63 em 2010. O setor de comércio também teve uma tendência semelhante ao de serviços, com uma queda na concentração de 1990 para 2000 e uma pequena recuperação em 2010, com QL igual a 0,64 neste ano. Já os setores industrial e de agricultura são os mais especializados, apesar da queda verificada de 1990 para 2010, o QL foi, respectivamente, igual a 2,29 e 1,92 em 2010.

Figura 5 - Quociente Locacional dos setores econômicos para o município de São Gonçalo do Amarante em, 1990, 2000 e 2010 


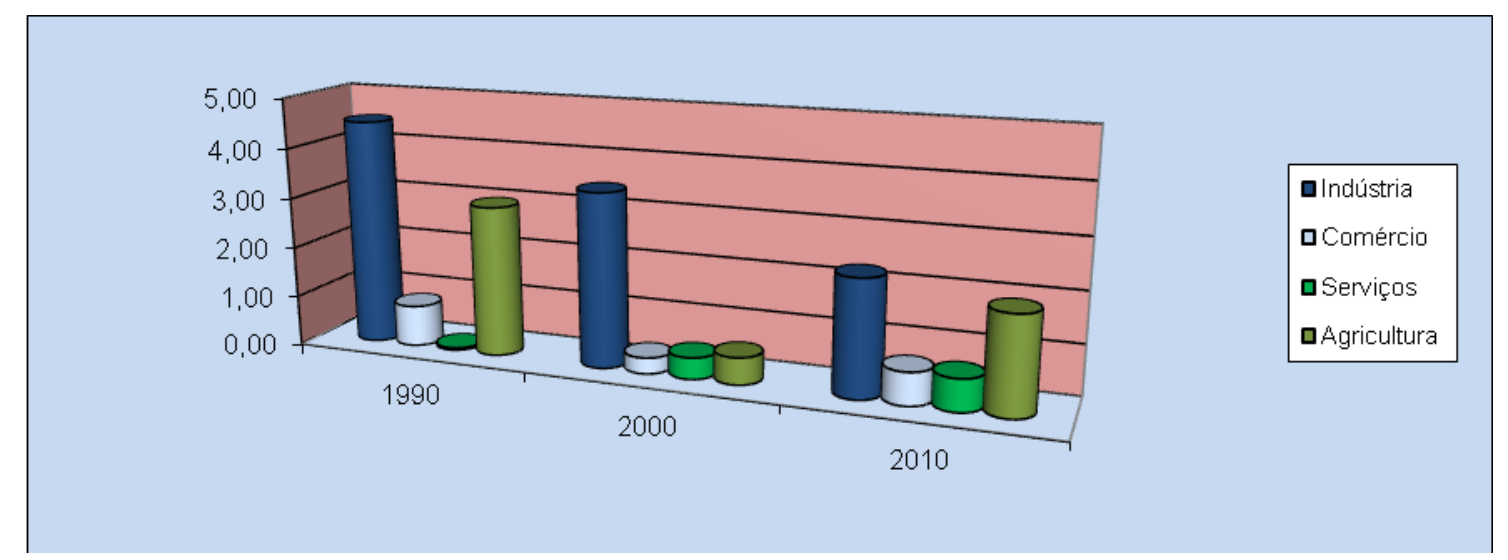

Fonte: Resultado da Pesquisa.

O município de Macaíba é limítrofe da cidade de Natal, de acordo com o CENSO (2010) aproximadamente $39 \%$ da população desse município residia na área rural. Em tal município verificou-se uma alta concentração no setor da indústria que ao longo do período teve uma significativa elevação, de modo que seu QL foi igual a 2,64 no ano de 2010. O setor agrícola também é especializado, teve uma queda do ano 2000 para 2010, mas seu QL é igual a 1,98 no ano de 2010. O setor terciário, ou seja, de serviços e comércio, teve uma tendência praticamente estável ao longo dos períodos, de modo que a especialização desse setor não ultrapassa o QL de 0,70, vide figura 6.

Figura 6 - Quociente Locacional dos setores econômicos para o município de Macaíba em 1990, 2000 e 2010

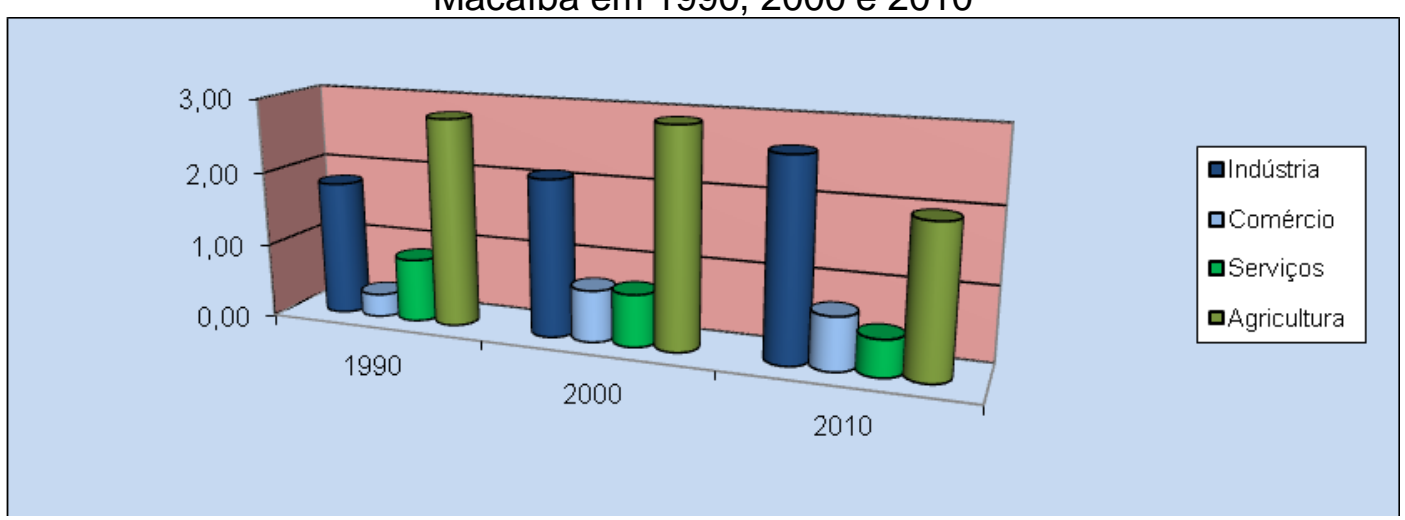

Fonte: Resultado da Pesquisa.

Por fim, nos demais municípios da RMN: São José do Mipibú, Extremoz, Monte Alegre, Nísia Floresta e Vera Cruz, verificou-se que eles possuem uma mesma tendência de especialização ao longo dos períodos de 1990, 2000 e 2010 no setor agrícola. São municípios que possuem uma vocação para atividades de agricultura e pecuária, que possuem grande proporção da população em áreas rurais. Com exceção do município de Extremoz em que verificou-se uma inversão de concentração do setor industrial para o de agricultura. Desse modo, observa-se que os municípios citados compõem a RMN institucionalmente, mas não possuem uma clara explicitação do fato urbano- metropolitano.

Notou-se que, à medida que os municípios se distanciam do polo, ou quanto menor o nível de integração à dinâmica de aglomeração, sua condição social tende a piorar. Através dos resultados é possível verificar que o setor Revista de Estudos Sociais | Ano 2017, N. 39, V. 20, Pag. 124 
terciário apresenta uma maior concentração nos municípios mais integrados ao centro urbano de Natal. Assim, as disparidades existentes no estado, especialmente na RMN, possuem particularidades históricas de cada região. Além do mais, as heranças da colonização ainda persistem nos tempos atuais, especialmente ao se verificar os setores produtivos envolvidos em cada mesorregião, como os que possuem maior concentração nas atividades tradicionais que utilizam mão de obra com pouca qualificação, como é o caso da agricultura. Outrossim, as diferenças de crescimento entre os municípios levantam o questionamento sobre os fatores determinantes de crescimento de cada região.

\section{CONSIDERAÇÕES FINAIS}

Este trabalho teve como objetivo principal analisar a dinâmica espacial dos setores econômicos, com ênfase no setor terciário, na Região Metropolitana de Natal nos anos de 1990, 2000 e 2010. Utilizaram-se os coeficientes locacionais para indicar as mudanças e tendências espaciais no que concerne o comportamento do emprego formal nas regiões.

Constatou-se que o setor terciário tem uma importância econômica para RMN para a geração de emprego formal, no entanto, esse setor tem vários desafios para serem superados, por exemplo, alguns municípios apesar de fazerem parte da RMN não possuem uma maior integração e dinamismo econômico. Com exceção dos municípios de Parnamirim, São Gonçalo e Macaíba, que ao longo das últimas décadas passou por um grande processo de urbanização e, portanto, um maior crescimento do leque de serviços oferecidos.

Muitos são os desafios para viabilizar a difusão dos impulsos gerados nas regiões ditas "centrais" para as regiões mais pobres. Nota-se que apenas identificar as aglomerações em uma determinada região e criar políticas para o desenvolvimento regional não irá, necessariamente, reverter o problema das desigualdades regionais no país. Verifica-se que a política nacional deve estar primordialmente relacionada com as especificidades de cada região.

O setor de serviços, ou terciário, é um setor empregador dos mais variados níveis de especialização e modalidades de emprego. Por exemplo, o comércio pode atrair pessoas com baixo nível de qualificação profissional. Tal setor também é caracterizado pelos altos índices de subemprego presente nos grandes centros urbanos, gerando condições de marginalização e precarização do trabalho.

É evidente a centralidade da cidade de Natal, pois verificou-se que as demais cidades que compõem a RMN apresentam um setor terciário com grandes fragilidades, principalmente, no tocante da existência de informalidade, em que exige-se pouca qualificação, pouca capacidade de empregar, e a oferta de serviços e produtos não é tão diversificada. Em síntese, a heterogeneidade intrínseca do setor terciário faz emergir a necessidade de fomentar políticas urbanas que potencializem o setor nas mais variadas regiões com menor dinamismo, possa reverter sua realidade de desequilíbrio geográfico existente. 


\section{REFERÊNCIAS BIBLIOGRÁFICAS}

ALVES, G. 2007. Precariedade e precarização do trabalho. In: Dimensões da reestruturação produtiva: ensaios de sociologia do trabalho. Londrina, Praxis; Bauru: Canal 6, 2007, 2 ${ }^{\mathrm{a}}$ Edição., p. 111-155. Disponível em: ftp://ftp.unilins.edu.br/leonides/Aulas/Form\%20Socio\%20Historica\%20do\%20Br \%202/Dimens_es\%20da\%20reestrutura_0\%20produtiva.PDF. Acesso em 05 de junho de 2016.

AZZONI, C.R. Indústria e reversão da polarização no Brasil. São Paulo: IPE-USP, 1986.

BENKO, G. A Ciência Regional. Oeiras (PO), 1999.

CLEMENTE, A. Economia regional e urbana. São Paulo: Atlas, 1994.

CORAGGIO, J. L. Las bases teóricas de la cuestion regional en America Latina (un enfoque critico). Mexico, Economia y Demografia 14(2) 141-178, 1980.

DRUCK, G. 2011. TRABALHO, PRECARIZAÇÃO E RESISTÊNCIAS: novos e velhos desafios? Salvador: CADERNO CRH, Salvador, v. 24, n. spe 01, p. 3757, $2011 . \quad$ Disponível em: http://www.scielo.br/pdf/ccrh/v24nspe1/a04v24nspe1.pdf. Acesso em 04 de junho de 2016.

GUIMARÃES NETO, L. (1997). Desigualdades e políticas regionais no desenvolvimento brasileiro: caminhos e descaminhos. Brasília, Planejamento e Políticas Públicas, IPEA, (15): , jun.

HADDAD, P. R.; ANDRADE, T. A.; Métodos de Análise Regional. In: HADDAD, P. R. et al Org. Economia Regional: Teorias e Métodos de Análise. Fortaleza: Banco do Nordeste do Brasil. ETENE, 1989.

HIRSCHMAN, A. A. estratégia do desenvolvimento econômico. São Paulo: Fundo de Cultura, 1961.

IPEADATA. Instituto De Pesquisa Econômica Aplicada (2012). Base de dados macroeconômicos. Disponível: <http: //www.ipeadata.gov.br>. Acesso em 15 de janeiro de 2016.

KON, A. Economia de serviços: teoria e evolução no Brasil. Rio de Janeiro: Elsevier, 2004.

LIPIETZ, A. O capital e seu espaço. São Paulo: Nobel, 1988.

LOSCH, A. The economics of location. Yale U. P., New Haven, 1954.

MARSHALL, A. (1982). Princípios de Economia. São Paulo: Abril Cultural, p. 231-238. 
MYRDAL, G. Teoria Econômica e Regiões Subdesenvolvidas- RJ- SAGA, $2^{\mathrm{a}}$ Ed., 1968.

RAIS (2012). Relatório Anual de Informações Sociais. Ministério do Trabalho e do Emprego.

SANTOS, M. Economia espacial. São Paulo: Edusp, 2003.

VON THÜNEN, JH 1826. O Estado isolado . Oxford: Pergamon Press, 1966. 